\title{
Bazı Tıbbi ve Aromatik Bitkilerin Köklendirme Özellikleri Üzerine Optimum IBA Dozlarının Saptanması
}

\author{
Mehmet Necat İGI* \\ Mardin Artuklu Üniversitesi, Kızlltepe Meslek Yüksekokulu, Bitkisel ve Hayvansal Üretim Bölümü \\ (ORCID: 0000-0003-1657-1169)
}

\begin{abstract}
$\ddot{\mathbf{O z}}$
$\mathrm{Bu}$ çalışma; perlit köklendirme ortamında farklı IBA dozlarının (kontrol, 1000, 1500, 2000, 2500, 3000, 3500, 4000, 4500, 5000 ve 5500 ppm) Lavanta, (Lavandula angustifolia Mill.), yağ gülü (Rosa damascena Mill.), kadıntuzluğu (Berberis thunbergii DC) ve biberiye (Rosmarinus officinalis L.) bitkilerinin çelikle köklendirilmeleri üzerine etkisini belirlemek amacıyla yürütülmüştür. Mardin Büyükşsehir Belediyesi Fidanlığından 2018 yılında anaç bitkilerden alınan çelikler, 11 farklı IBA dozunda maruz bırakılarak perlitte, sera ortamında dikimleri yapılmıştır. Köklendirmeye bırakılan çeliklerde; kök sayısı, kök uzunluğu ve köklenme oranları hesaplanmıştır. Çalışmada; IBA dozlarının kadıntuzluğu bitkisinde köklenme oranları ve biberiye bitkisinde ise kök uzunlukları üzerine etkisi önemsiz, diğer özellikler üzerine etkileri istatistiksel yönden önemli bulunmuştur. En yüksek kök sayısı lavanta bitkisinde 25.10 adet/bitki ile 4500 ppm, yağ gülü bitkisinde 24.86 adet/bitki ile 4000 ppm, kadıntuzluğunda 15.95 adet/bitki ile 3000 ppm ve biberiyede 33.31 adet/bitki ile 5000 ppm IBA dozu uygulamalarından elde edilmiştir. Kök uzunluğu değerleri, biberiye hariç olmak üzere, lavantada $24.80 \mathrm{~cm}$ ile 4000 ppm, yağ gülünde $23.99 \mathrm{~cm}$ ile 3000 ppm ve kadıntuzluğu bitkisinde $13.75 \mathrm{~cm}$ ile $4000 \mathrm{ppm}$ IBA dozlarında tespit edilmiştir. En yüksek köklenme oranlarının, kadıntuzluğu bitkisi hariç olmak üzere, lavantada 3500 ve 4000 ppm IBA dozlarında \%90.00, yağ gülünde 4500 ppm IBA dozunda \% 76.67 ve biberiyede 5000 ve 5500 IBA dozlarında \%93.33 olduğu saptanmıştır.
\end{abstract}

Anahtar kelimeler: Perlit, IBA dozu, köklenme oranı, kök sayısı, kök uzunluğu.

\section{Determination of Optimum IBA Doses on Rooting Properties of Some Medicinal and Aromatic Plants}

\begin{abstract}
This study was conducted to determine the effect of the different IBA doses (control, 1000, 1500, 2000, 2500, 3000, 3500, 4000, 4500, 5000 and 5500 ppm) on the rooting of Lavender, (Lavandula angustifolia Mill.), damask rose (Rosa damascena Mill.), barberry (Berberis thunbergii DC) and rosemary (Rosmarinus officinalis L.) with cuttings in a perlite rooting medium. Cuttings which were taken from the rootstock plants of Mardin Metropolitan Municipality Nursery in 2018 were subjected to 11 different IBA doses for 5 seconds and planted in the perlite in a greenhouse environment. The number of roots, root lengths and rooting rates were calculated in the cuttings left for rooting for 75 days on average. In the study, the effect of the IBA doses on the rooting rates of barberry and the root lengths of rosemary was found insignificant; but their effect on 4 different medical plant cuttings was found statistically significant. The highest number of roots was obtained as 25.10 piece/plant in lavender from $4500 \mathrm{ppm}$ IBA-dose implementation, as 24.86 piece/plant in damask rose from 4000 ppm IBA-dose implementation, as 15.95 piece/plant in barberry from $3000 \mathrm{ppm}$ IBA-dose implementation and as 33.31 piece/plant in rosemary from $5000 \mathrm{ppm}$ IBA-dose implementation. Except for rosemary, the values of root lengths were found as $24.80 \mathrm{~cm}$ in lavender in $4000 \mathrm{ppm}$ IBA dose, as $23.99 \mathrm{~cm}$ in damask rose in 3000 ppm IBA dose and as $13.75 \mathrm{~cm}$ in barberry in $4000 \mathrm{ppm}$ IBA dose. The highest rooting rates were observed as $90.00 \%$ in lavender in 3500 and 4000 ppm IBA doses, $76.67 \%$ in damask rose in 4500 ppm IBA dose and $93.33 \%$ in rosemary in 5000 and 5500 IBA doses.
\end{abstract}

Keywords: Perlite, IBA dose, rooting rate, number of roots, root length.

\footnotetext{
*Sorumlu yazar: necatizgi@ hotmail.com

Geliş Tarihi: 11.09.2019, Kabul Tarihi: 06.04.2020
} 


\section{Giriş}

Vejetatif çoğaltım, özellikle belirli türlerin tohum çimlenme oranı \%50'den az olduğunda kullanılır. Ayrıca bu yöntem bitkilerin yetiştirme süreci zahmetli ve karmaşık olan aromatik ve tıbbi bitki türlerin çoğu için de geçerlidir $[1,2]$. Kalitesi iyi olan tiplerin çoğaltılmasında kök sürgünleri ve çelikle çoğaltma yaygın olarak kullanılmaktadır. [3, 4]. Çelikle çoğaltma sayesinde aşı uygulamalarında görülen bazı güçlükler ortadan kaldırılarak daha hızlı ve seri fidan üretimi yapılabilmektedir [5].

Köklendirme işlemlerini kolaylaştırmanın bir yolu, daha uniform ve kuvvetli kökler oluşturan, fidelerin oluşum sürecini hızlandıran, kök oluşumunu teşvik eden sentetik oksinler gibi bitki büyüme düzenleyicilerinin kullanılmasıdır [6,7]. Oksin katkısı birçok çalışmada doğrulanmıştır ve gerekli konsantrasyonlar türden türe değişmektedir [8]. Genel olarak bitkiler konsantrasyondaki artışın teşvik edici veya fitotoksik hale geldiği uygun bir oksin seviyesine kadar uyarıma kademeli olarak yanıt verir [7]. Fitohormonların, özellikle de büyüme düzenleyicileri olarak oksinlerin köklü fidan üretiminde uygulanmasının amacı, fide ve bitki sayısını arttırmak, köklenme süresini kısaltmak, bitki başına kök sayısını artırmak ve kök sistemin bütünlüğünü arttırmaktır [9]. IBA ve NAA, çoğunlukla bitki çeliklerinin sulanması sırasındaki kararlılıkları nedeniyle ticari olarak en çok kullanılan büyüme düzenleyicileridir $[10,11]$. Bazı bitki türleri, büyüme düzenleyicileri uygulanmadan zor bir şekilde köklenir, bu nedenle optimum IBA veya NAA konsantrasyonunun uygulanmas1 zorunludur [12]. Kimyasal büyüme düzenleyicilerden olan IBA'nın 2500 ila 4000 ppm aralığında elma, kuru erik ve zeytinlerde yarı sert odun çeliklerinde kullanıldığı ve çeliklerde adventif kök oluşumunu teşvik etmesi bakımından en fazla etkiye sahip olduğu bildirilmiştir [13,14]. Ginkgo biloba L. bitkisinde IBA 4000 ppm'de kök kesimlerinde köklenme yüzdesini artırdığı, ancak daha yüksek dozda köklenmenin azaldığı bildirilmiştir [15]. Hoque [16], çay bitkisi çeliklerinde (Camellia sinensis L.) IBA ile muamele edilmiş kısımların, kontrol grubu oranları ile karşılaştırıldığında köklenme hızı, kök uzunluğu, kök sayısı, sürgün uzunluğu ve hayatta kalma oranı üzerinde daha iyi etki gösterdiğini belirtmiştir. Gudeva ve ark. [17], biberiyede IBA hormon uygulamasının diğer ticari hormonlara göre (IAA ve NAA) daha etkili olduğunu, alınan çeliklerde, kök uzunluğu $(25.17 \mathrm{~cm})$, köklenen çelik sayısı (46 adet) ve köklenme oranının (\%92) diğer uygulamalarla karşılaştırıldığında önemli derecede yüksek olduğunu bildirmişlerdir. Saffari ve Saffari [18], farklı köklendirme ortamları ve IBA dozlarında yaptıkları çalışmada en iyi sonucun perlitte ve 4000 ppm IBA ile elde edildiğini belirtmişlerdir. Daha önceki yapılan çalışmalar bitkilerin farklı köklendirme hormon ve dozlarına tepkilerinin değişiklik gösterebileceğini ortaya koymaktadır. Bu bağlamda; yürütülen bu araştırmaperlit ortamında, farklı IBA dozlarının lavanta, yağ gülü, kadıntuzluğu ve biberiye çeliklerinde adventif köklenme üzerine etkilerini belirlemek amaciyla yürütülmüştür.

\section{Materyal ve Metot}

$\mathrm{Bu}$ çalışma Mardin Büyükşehir Belediyesi fidanlığında anaç olarak yetiştirilen lavanta (Lavandula angustifolia), yağ gülü (Rosa damascena Mill.), kadıntuzluğu (Berberis thunbergii) ve biberiye (Rosemary officinalis) bitkilerinin bir yıllık sürgünlerinden alınan çelikler kullanılarak yürütülmüsstür. 23-25 Şubat 2018 tarihinde her bitkiden $13-15 \mathrm{~cm}$ uzunluğunda, toplam 330 adet bitki çeliği hazırlanmıştır. Çelikler perlit ortamında 1000, 1500, 2000, 2500, 3000, 3500, 4000,4500, 5000, 5500 ppm ve kontrol grubu olmak üzere 11 farklı IBA dozunda, üç tekerrürlü olarak düzenlenmiştir. Denemede her bir tekerrürde 10 adet çelik olmak üzere her bitki grubundan 30 adet bitki çeliği kullanılmıştır. Çeliklerin 5cm'lik alt kısımları; Indol-3 bütirik asitte, 5 'er saniye bekletilmiştir (kontrol grubu hariç). Sera sıcaklığı infrared isıtıcılarla $25^{\circ} \mathrm{C}$ 'de sabit tutulmuş olup bitkiler düzenli olarak sisleme başlıklarıyla sulanmıştır. Uygulamanın 75. gününde bitkiler sökülerek köklenme oranı (\%), kök sayısı (adet) ve kök uzunluğu $(\mathrm{cm})$ değerleri hesaplanmıştır. Deneme, Tesadüf Parselleri Deneme Deseninde 3 Tekerrürlü olarak düzenlenmiştir. Elde edilen verilerin istatistiksel analizleri MSTAT-C Programı kullanılarak yapılmış ve önem derecelerine göre ortalamalar arasındaki farklılığın belirlenmesinde LSD Testi uygulanmıştır. 


\section{Bulgular ve Tartışma}

\subsection{Lavanta (Lavandula angustifolia)}

Lavanta bitkisinde farklı IBA dozlarında incelenen tüm özellikler bakımından (kök sayısı, kök uzunluğu ve köklenme oranı) bakımından her biri arasındaki fark istatistiksel yönden önemli bulunmuştur. En yüksek kök sayısı 4500 ppm IBA dozundan (25.10 adet) elde edilirken en düşük kök sayısı 1500 ppm IBA dozundan (17.04 adet) elde edilmiştir. En yüksek kök uzunluğu 4000 ppm IBA dozunda (24.80 $\mathrm{cm})$ elde edilirken en düşük kök sayısı kontrol grubundan $(17.44 \mathrm{~cm})$ elde edilmiştir. En yüksek köklenme oranı 2500, 3500 ve 4000 ppm IBA dozlarında (\%90) elde edilirken en düşük kök sayısı kontrol grubundan (\%53.33) elde edilmiştir (Tablo 1).

Hoque [16], çay bitkisinde (Camellia sinensis L.) yürüttüğü IBA doz oranı çalışmasında en yüksek köklenme oranının (\%79.85) 4000 ppm'de elde ettiğini, 6000 ppm çözeltide ise bu oranın bir miktar düştüğünü (\%79.78) belirtmiş̧ir. Xian ve ark. [19], indol-3-bütirik asite hızlı daldırma yöntemi (IBA) ile ön işleme tabi tutulmuş Paeonia çeliklerinin, en iyi köklenme özelliklerine ( köklenme oranı $\%$ 86.7, kök sayısı 23.1 ve kök uzunluğu $6.4 \mathrm{~cm}$ ) sahip olduğunu belirtmişlerdir.

Tablo 1. Farklı IBA dozlarının perlit ortamında lavantanın köklenme özellikleri üzerine etkisi

\begin{tabular}{cccc}
\hline IBA Doz & & Lavanta $($ Lavandula angustifolia $)$ & \\
& Kök sayısı (adet) & Kök uzunluğu $(\mathrm{cm})$ & Köklenme oranı $(\%)$ \\
\hline $\mathbf{1 0 0 0}$ & $18.36 \mathrm{c}$ & $17.44 \mathrm{~d}$ & $53.33 \mathrm{~d}$ \\
\hline $\mathbf{1 5 0 0}$ & $20.12 \mathrm{bc}$ & $18.00 \mathrm{~cd}$ & $66.67 \mathrm{~cd}$ \\
\hline $\mathbf{2 0 0 0}$ & $17.04 \mathrm{c}$ & $19.87 \mathrm{~cd}$ & $73.33 \mathrm{bc}$ \\
\hline $\mathbf{2 5 0 0}$ & $18.31 \mathrm{c}$ & $20.64 \mathrm{bc}$ & $73.33 \mathrm{bc}$ \\
\hline $\mathbf{3 0 0 0}$ & $20.63 \mathrm{abc}$ & $20.62 \mathrm{bcd}$ & $90.00 \mathrm{a}$ \\
\hline $\mathbf{3 5 0 0}$ & $17.96 \mathrm{c}$ & $18.88 \mathrm{~cd}$ & $80.00 \mathrm{abc}$ \\
\hline $\mathbf{4 0 0 0}$ & $19.36 \mathrm{bc}$ & $23.26 \mathrm{ab}$ & $90.00 \mathrm{a}$ \\
\hline $\mathbf{4 5 0 0}$ & $20.51 \mathrm{abc}$ & $24.80 \mathrm{a}$ & $90.00 \mathrm{a}$ \\
\hline $\mathbf{5 0 0 0}$ & $25.10 \mathrm{a}$ & $24.50 \mathrm{a}$ & $86.67 \mathrm{ab}$ \\
\hline $\mathbf{5 5 0 0}$ & $23.92 \mathrm{ab}$ & $23.91 \mathrm{a}$ & $76.67 \mathrm{abc}$ \\
\hline Ortalama & $19.01 \mathrm{c}$ & $23.22 \mathrm{ab}$ & $73.33 \mathrm{bc}$ \\
\hline LSD & 20.03 & 21.37 & 77.57 \\
\hline
\end{tabular}

\subsection{Yağ gülü (Rosa damascena)}

Yağ gülü bitkisinde incelenen köklenme özelliklerinin tümünde, farklı IBA dozlarının değerler arasında ortaya çıkan fark önemli bulunmuştur. En yüksek kök sayısı 3500, 4000 ve 4500 ppm dozlarından $(24.45,24.86$ ve 24.40 adet), en düşük kök sayısı kontrol grubundan (11.66 adet) elde edilmiştir. En yüksek kök uzunluğu $(23.99 \mathrm{~cm}) 4500$ ppm IBA dozunda, en düşük kök uzunluğu $(12.04 \mathrm{~cm}) 1000$ ppm IBA dozunda elde edilmiştir. Köklenme oranında en yüksek değer (\%76.67) 4500 ppm dozunda, en düşük değer (\%36.67) kontrol grubunda olduğu tespit edilmiştir (Tablo 2).

Fragoso ve ark. [20] Prunus serrulata bitki çeliklerine kontrol grubu dâhil, uyguladıkları 21 farklı IBA dozları arasında en yüksek köklenme oranının (\%80) 2700 ppm olduğunu belirtmişlerdir. Kaşka ve Yılmaz [21], Rosa setigera türünde yaptıkları bir çalışmada bitki çeliklerinin köklenmediğini bildirmişlerdir. Güneş ve Yalçın [22], çeşitli Rosa türleri üzerinde, yaptıkları bir çalışmada türler arasında sürgün çeliklerinin köklenme durumlarında farklılıklar olduğunu, Rosa hemisphaerica türünün çeliklerinde köklenmenin görülmediğini bildirmişlerdir. 
Tablo 2. Farklı IBA dozlarının perlit ortamında yağ gülünün köklenme özellikleri üzerine etkisi

\begin{tabular}{cccc}
\hline IBA Doz & & Yă̆ gülü $($ Rosa damascena $)$ & \\
& Kök sayısı (adet) & Kök uzunluğu $(\mathrm{cm})$ & Köklenme oranı $(\%)$ \\
\hline $\mathbf{1 0 0 0}$ & $11.66 \mathrm{~d}$ & $14.27 \mathrm{de}$ & $36.67 \mathrm{e}$ \\
\hline $\mathbf{1 5 0 0}$ & $13.37 \mathrm{~d}$ & $12.04 \mathrm{e}$ & $43.33 \mathrm{de}$ \\
\hline $\mathbf{2 0 0 0}$ & $15.65 \mathrm{~cd}$ & $16.78 \mathrm{~cd}$ & $43.33 \mathrm{de}$ \\
\hline $\mathbf{2 5 0 0}$ & $17.92 \mathrm{bc}$ & $18.06 \mathrm{bcd}$ & $53.33 \mathrm{~cd}$ \\
\hline $\mathbf{3 0 0 0}$ & $20.81 \mathrm{ab}$ & $20.15 \mathrm{abc}$ & $53.33 \mathrm{~d}$ \\
\hline $\mathbf{3 5 0 0}$ & $22.19 \mathrm{ab}$ & $23.55 \mathrm{a}$ & $66.67 \mathrm{ab}$ \\
\hline $\mathbf{4 0 0 0}$ & $24.45 \mathrm{a}$ & $21.37 \mathrm{ab}$ & $60.00 \mathrm{c}$ \\
\hline $\mathbf{4 5 0 0}$ & $24.86 \mathrm{a}$ & $21.66 \mathrm{~b}$ & $66.67 \mathrm{~b}$ \\
\hline $\mathbf{5 0 0 0}$ & $24.40 \mathrm{a}$ & $23.99 \mathrm{a}$ & $76.67 \mathrm{a}$ \\
\hline $\mathbf{5 5 0 0}$ & $19.55 \mathrm{bc}$ & $17.96 \mathrm{bcd}$ & $70.00 \mathrm{ab}$ \\
\hline Ortalama & $19.45 \mathrm{bc}$ & $19.29 \mathrm{bc}$ & $46.67 \mathrm{de}$ \\
\hline LSD & 19.48 & 19.01 & 56.06 \\
\hline
\end{tabular}

\subsection{Kadıntuzluğu (Berberis thunbergii)}

Kadıntuzluğu bitkisinde; kök sayısı ve kök uzunluğu değerleri arasındaki farklar istatistiki yönden önemli, köklenme oranı değerleri arasındaki fark önemsiz bulunmuştur. En yüksek kök sayısı (15.95 adet) 3000 ppm IBA dozundan, en düşük kök sayısı (5.38 adet) kontrol grubundan elde edilmiştir. En yüksek kök uzunluğu $(13.75 \mathrm{~cm}) 4000$ ppm IBA dozundan, en düşük kök uzunluğu $(4.33 \mathrm{~cm})$ kontrol grubundan elde edilmiştir. İstatistiksel olarak önemli olmamakla birlikte en yüksek köklenme oranı (\%63.3) 2500 ppm IBA dozunda, en düşük köklenme oranı (\%40.0) kontrol grubundan elde edilmiştir (Tablo 3).

Juglans regia L. türünün odun çelikleri üzerinde IBA'nın etkisinin araştırıldığı bir çalışmada, hiçbir çelikte köklenmenin olmadığı belirtilmiştir [23]. Gudeva ve ark. [17], IAA, IBA, NAA ve ticari köklendirme ürünleri ile yapılan bir çalışmada en iyi köklenme etkisinin, IBA (\% 54) ve NAA (\% 50) uygulamalarıyla elde edildiğini, bununla birlikte en fazla kök uzunluğunun ticari köklendirme ürününden $(5.60 \mathrm{~cm})$ ve kontrol grubu çeliklerinden $(5.25 \mathrm{~cm})$ işlem gördüğ̈̈ belirtmişlerdir.

Tablo 3. Farklı IBA dozlarının perlit ortamında kadıntuzluğunun köklenme özellikleri üzerine etkisi

\begin{tabular}{cccc}
\hline IBA Doz & & Kadıntuzluğu (Berberis thunbergii) & \\
& Kök sayısı (adet) & Kök uzunluğu $(\mathrm{cm})$ & Köklenme oranı $(\%)$ \\
\hline $\mathbf{0}$ & $5.38 \mathrm{~d}$ & $4.33 \mathrm{~d}$ & 40.0 \\
\hline $\mathbf{1 0 0 0}$ & $8.79 \mathrm{c}$ & $6.54 \mathrm{~d}$ & 50.0 \\
\hline $\mathbf{1 5 0 0}$ & $15.25 \mathrm{ab}$ & $6.79 \mathrm{~d}$ & 56.66 \\
\hline $\mathbf{2 0 0 0}$ & $15.20 \mathrm{ab}$ & $10.25 \mathrm{bc}$ & 53.3 \\
\hline $\mathbf{2 5 0 0}$ & $14.83 \mathrm{ab}$ & $12.59 \mathrm{ab}$ & 63.3 \\
\hline $\mathbf{3 0 0 0}$ & $15.95 \mathrm{a}$ & $12.40 \mathrm{ab}$ & 56.6 \\
$\mathbf{3 5 0 0}$ & $14.21 \mathrm{ab}$ & $11.99 \mathrm{ab}$ & 53.3 \\
\hline $\mathbf{4 0 0 0}$ & $14.83 \mathrm{ab}$ & $13.75 \mathrm{a}$ & 56.66 \\
\hline $\mathbf{4 5 0 0}$ & $13.38 \mathrm{~b}$ & $11.50 \mathrm{abc}$ & 50.00 \\
\hline $\mathbf{5 0 0 0}$ & $14.25 \mathrm{ab}$ & $12.45 \mathrm{ab}$ & 43.3 \\
\hline $\mathbf{5 5 0 0}$ & $13.33 \mathrm{~b}$ & $9.417 \mathrm{c}$ & 43.3 \\
\hline Ortalama & 13.22 & 10.18 & 51.51 \\
\hline LSD & 2.42 & 2.544 & Ö.d \\
\hline
\end{tabular}

Ö.d.: Önemli değil 


\subsection{Biberiye (Rosmarinus officinalis)}

Biberiye bitkisinde kök sayısı ve köklenme oranı değerleri arasındaki fark istatistiki yönden önemli, kök uzunluğu değerleri arasındaki fark önemsiz bulunmuştur. En yüksek kök sayısı (33.31 adet) 5000 ppm IBA dozunda, en düşük kök sayısı (12.53 adet) kontrol grubundan elde edilmiştir. İstatistiksel olarak önemli olmamakla birlikte en yüksek kök uzunluğu $(27.73 \mathrm{~cm}) 5000$ ppm IBA dozundan, en düşük kök uzunluğu $(24.17 \mathrm{~cm}) 2500$ ppm dozundan elde edilmiştir. En yüksek köklenme oranı (\%93.33) 3500, 5000 ve 5500 ppm IBA dozunda, en düşük köklenme oranı (\%66.67) kontrol grubundan elde edilmiştir (Tablo 4).

Kara ve ark. [24], biberiye çeliklerinde yapmış oldukları çalışmada en fazla kök sayısını (25.1 adet), kök uzunluğu $(5.9 \mathrm{~cm})$ ve köklenme oranlarının (\%75.7) 4000 ppm IBA dozundan elde ettiklerini belirtmişlerdir. Hoque [16], çay bitkisinde (Camellia sinensis L.) IBA çözelti oranının arttıkça kök uzunluğunun arttığını, maksimum kök uzunluğunu $(4.85 \mathrm{~cm}) 4000$ ppm dozundan elde ettiğini, 6000 ppm dozunda kök uzunluğunun bir miktar düştüğünü belirtmiştir. Gudeva ve ark. [17], IAA, IBA, NAA ve ticari köklendirme ürünleri ile yaptıkları çalışmada biberiye çeliklerinde en iyi simülatif etkiyi IBA'nın gösterdiğini, çelik uzunluğunun $25.17 \mathrm{~cm}$, köklenmiş çelik sayısının 46 adet, köklenme oranının \%92 olduğu bu uygulama, kontrol grubu dâhil diğer uygulamalara oranla bir hayli yüksek olduğunu bildirmişlerdir.

Tablo 4. Farklı IBA dozlarının perlit ortamında biberiyenin köklenme özellikleri üzerine etkisi

\begin{tabular}{cccc}
\hline IBA Doz & & Biberiye (Rosmarinus officinalis) & \\
\cline { 2 - 4 } & Kök sayıs (adet) & Kök uzunluğu $(\mathrm{cm})$ & Köklenme oranı (\%) \\
\hline $\mathbf{1 0 0 0}$ & $12.53 \mathrm{e}$ & 24.57 & $66.67 \mathrm{~d}$ \\
\hline $\mathbf{1 5 0 0}$ & $17.74 \mathrm{de}$ & 24.92 & $80.00 \mathrm{bc}$ \\
\hline $\mathbf{2 0 0 0}$ & $23.78 \mathrm{~cd}$ & 24.94 & $76.67 \mathrm{~cd}$ \\
\hline $\mathbf{2 5 0 0}$ & $24.89 \mathrm{bc}$ & 26.25 & $80.00 \mathrm{bc}$ \\
\hline $\mathbf{3 0 0 0}$ & $25.62 \mathrm{bc}$ & 24.17 & $83.33 \mathrm{abc}$ \\
\hline $\mathbf{3 5 0 0}$ & $25.41 \mathrm{bc}$ & 25.58 & $80.00 \mathrm{bc}$ \\
\hline $\mathbf{4 0 0 0}$ & $27.03 \mathrm{abc}$ & 24.77 & $93.33 \mathrm{a}$ \\
\hline $\mathbf{4 5 0 0}$ & $28.50 \mathrm{abc}$ & 24.88 & $90.00 \mathrm{ab}$ \\
\hline $\mathbf{5 0 0 0}$ & $31.35 \mathrm{ab}$ & 26.42 & $83.33 \mathrm{abc}$ \\
\hline $\mathbf{5 5 0 0}$ & $33.31 \mathrm{a}$ & 27.73 & $93.33 \mathrm{a}$ \\
\hline Ortalama & $30.39 \mathrm{ab}$ & 25.92 & $93.33 \mathrm{a}$ \\
\hline LSD & 25.50 & 25.46 & 83.63 \\
\hline Oad & 6.57 & Ö.d. & 12.33 \\
\hline
\end{tabular}

Ö.d.: Önemli değil

\section{Sonuçlar}

Çalışmada lavanta, yağ gülü, kadıntuzluğu ve biberiye bitki çeliklerinde kök sayısı, kök uzunluğu ve köklenme oranı değerleri üzerinde farklı IBA dozlarının etkisi istatistiksel olarak önemli bulunmuştur. Köklenme değerlerinde, artan IBA dozlarına paralel olarak genelde bir artış gözlenmiştir. 5500 ppm IBA dozuna maruz bırakılan bitki çelikleri köklenme özelliklerinde duraksama veya gerilemeye neden olduğu tespit edilmiştir. En yüksek kök sayıs1, kök uzunluğu ve köklenme oranı; lavantada ve yağ gülünde 4500 ppm, kadıntuzluğunda 3500 ppm, biberiyede 5000 ppm IBA dozlarında kaydedilmiştir.

\section{Yazarların Katkısı}

Tüm bitkilerin toplanıp hazırlanması, köklendirme çalışmalarının yapılması ve makalenin yazımı ve yorumlanması Mehmet Necat İZGİ tarafından gerçekleştirilmiştir.

\section{Çıkar Çatışması Beyanı}

Yazarlar arasında herhangi bir çıkar çatışması bulunmamaktadır. 


\section{Araştırma ve Yayın Etiği Beyanı}

Yapılan çalışmada, araştırma ve yayın etiğine uyulmuştur. Bu çalışmada etik kurul izni gerekmemektedir.

\section{Kaynaklar}

[1] Farooqi A.A., Sreeramu B.S. 2004. Cultivation of Medicinal and Aromatic Crops. Hyderabad: Universities Press (India) Private Limited.

[2] Hartmann H.T., Kester D.E., Davies F.T., Geneve R.L. 1997. Plant Propagation: principles and practices. New Jersey: Prentice Hall, Inc.

[3] Bekçi B., Dinçer D., Var M., Yahyaoğlu Z. 2010. Trabzon ve Yöresinde Doğal olarak Bulunan Bazı Meyveli Bitkilerin Yetiştirme Teknikleri ve Peyzaj Mimarlığında Değerlendirilmesi. III. Ulusal Karadeniz Ormanc1l1k Kongresi, 20-22 May1s 2010, IV: 1456-1466.

[4] İslam A. 2005. Karayemiş Yetiştiriciliği ve Önemi. Ege Karadeniz Dergisi, 2 (4).

[5] Yılmaz M. 1992. Bahçe Bitkileri Yetiştirme Tekniği. Çukurova Üniversitesi Basımevi, 151s., Adana.

[6] Pizzatto M., Junior A.W., Luckman D., Pirola K., Cassol D.A., Sergio M.M. 2011. Effects of IBA concentration, collection time and cutting length on hibiscus cutting propagation. Revista Ceres, 58 (4): 487-492.

[7] Pop T.I., Doru P., Bellini C. 2011. Auxin control in the formation of adventitious roots. Notulae Botanicae Horti Agrobotanici, 39 (1): 307-316.

[8] Abu-Zahra T.R., Al-Shadaideh A.N., Abubaker S.M., Qrunfleh I.M. 2013 Influence of auxin concentrations on different ornamental plants rooting. International Journal of Botany, 9 (2): 96 99.

[9] Kulevnova S. 2011. Important medicinal and aromatic plants in South-East Europe in relation with their medicinal and other industrial utilization: Republic of Macedonia. Institute of Organic Chemistry with Centre of Phytochemistry, BAS, Sofia, Bulgaria.

[10] Blythe E.K. 2012. Current options for using auxin solutions in cutting propagation. Acta Horticulture, 1: 341-343.

[11] Boyer N.Z., Graves W.R. 2009. NAA is more effective than IBA for rooting stem cuttings of two Nyssa spp. J Environ Hortic., 27 (3): 183-187.

[12] Taleb R.A., Ahmad N.A. 2013. Influence of auxin concertation on different ornamental plants. International Journal of Botany, 9 (2): 96-99.

[13] Al-Sagri F., Alderson P.G. 1996. Effect of IBA, cutting type and rooting media on rooting of Rosa centifolia. Journal of Horticultural Science, 71: 729-737.

[14] Bhattacharya S.K., Balakrishna M. 1986. Standardization of propagation of Hibiscus rosasinensis L. from stem cutting. South Indian Hort., 34: 158-166.

[15] Barzgar T.L. 2003. The effects of medium and different concentration of IBA on Ginkgo biloba cuttings. M. Sc. Thesis in Horticulture, University of Tehran, 72p (in Persian).

[16] Hoque M.E. 2016. Effect of Indole Butyric Acid on Raising Plants from Stem Cuttings of Tea (Camellia sinensis L.) in the Nursery. The Agriculturists a Scientific Journal of Krishi Foundation, 14 (2): 124-129.

[17] Gudeva L.K., Trajkova F., Mihajlov L., Troicki J. 2017. Influence of Different Auxins on Rooting of Rosemary, Sage and Elderberry. Annual Research \& Review in Biology, 12 (5): 1-8.

[18] Saffari M., Saffari V.R. 2012. Effects of media and indole butyric acid (IBA) concentrations on hopbush (Dodoneae viscosa L.) cuttings in green house. Annals of Forest Research. Ann. For. Res., 55 (1): 61-68.

[19] Xian F.G., Xiling F., Dekui Z., Yan M. 2008. Effect of auxin treatments, cuttings collection date and initial characteristics on Paeonia 'Yang Fei Chu Yu' cutting propagation. Scientia Horticulturae, 119: 177-181.

[20] Fragoso R.O., Stuepp C.A., Rickli H.C., Ribas K.C.Z., Koehler H.S. 2017. Maximum efficiency concentration of indole butyric acid in promoting the rooting of Japanese Flowering Cherry. Ciência Rural, Santa Maria, 47 (01): e20150894. http://dx.doi.org/10.1590/01038478cr20150894. 
[21] Kaşka N., Yılmaz M., 1974. Bahçe Bitkileri Yetiştirme Tekniği. Çukurova Üniversitesi Yayını, $79 \mathrm{p}$.

[22] Güneş T., Yalçın İ. 1990. Rosa (Rosa canina, Rosa hemisphaerica, Rosa heckeliana) Sürgün Çeliklerinde Kök Oluşumu ve Karbonhidrat İçeriği Üzerine Bir Araştırma. Çukurova Üniversitesi, Fen Edebiyat Fakültesi Fen Bilimleri Dergisi, 13: 41-52.

[23] Güneş T. 1999. An Investigation on Rooting of Juglans regia L. Hardwood Cuttings. Tr. J. of Botany, 23: 367-372.

[24] Kara N., Baydar H., Erbaş S. 2011. Farklı Çelik Alma Dönemleri ve IBA Dozlarının Bazı Tıbbi Bitkilerin Köklenmesi Üzerine Etkileri. Batı Akdeniz Tarımsal Araştırma Enstitüsü Derim Dergisi, 28 (2): 71-81. 